\title{
UMA REVISÃO SISTEMÁTICA SOBRE METODOLOGIAS ATIVAS NO ENSINO DA MATEMÁTICA: APRENDIZAGEM ATIVA, PROTAGONISMO DOS ESTUDANTES
}

\section{A SYSTEMATIC REVIEW ON ACTIVE METHODOLOGIES IN MATHEMATICS TEACHING: ACTIVE LEARNING, STUDENT PROTAGONISM}

\section{UNA REVISIÓN SISTEMÁTICA DE LAS METODOLOGÍAS ACTIVAS EN LA ENSEÑANZA DE LAS MATEMÁTICAS: APRENDIZAJE ACTIVO, PROTAGONISMO DEL ESTUDIANTE}

\author{
Josimauro Borges de Carvalho \\ ${ }^{1}$ Mestre em Matemática, Universidade Federal do Piauí (UFPI). Professor Assistente na Universidade do Estado do Amazonas (UEA), \\ Tefé, Amazonas, Brasil; E-mail do autor correspondente: jbcarvalho@,uea.edu.br.
}

Recebido: 05/10/2021| Aprovado: 03/11/2021 | Publicado: 02/12/2021

\begin{abstract}
Resumo: As metodologias ativas são aplicadas no processo de ensino-aprendizagem com efeito de promover uma assimilação ativa dos conteúdos, permitindo que o educando assuma o protagonismo na aquisição do conhecimento. A utilização destas metodologias torna possível um envolvimento maior do aluno com a sua aprendizagem, aumentando as chances de compreender, de forma contextualizada, o que lhe é apresentado. Nesse sentido, afirma-se que objetivo geral do presente estudo é o de analisar a importância das metodologias ativas para o ensino da matemática. A metodologia utilizada na elaboração desta pesquisa é a revisão bibliográfica construída por meio da análise de artigos científicos publicados e selecionados por meio das bases de dados Google Acadêmico e SciELO, obedecendo ao recorte temporal que compreende os anos de 2020 a junho de 2021. Verificou-se que a utilização das metodologias ativas para o ensino da matemática potencializa a assimilação dos conteúdos e permite uma aprendizagem mais significativa por parte dos alunos. Isso, pois com a apresentação dos conteúdos de forma contextualizada se torna possível atribuir sentido aos temas curriculares de matemática que estão sendo trabalhados.
\end{abstract}

Palavras-chave: Educação. Exatas. Curriculares. Conteúdos.

Abstract: The active methodologies are applied in the teaching-learning process in order to promote an active assimilation of the contents, allowing the student to take the lead in the acquisition of knowledge. The use of these methodologies makes possible a greater involvement of the student with his learning, increasing the chances of understanding, in a contextualized way, what is presented to him. In this sense, it is stated that the general objective of this study is to analyze the importance of active methodologies for the teaching of mathematics. The methodology used in the preparation of this research is the literature review built through the analysis of scientific articles published and selected through the Google Academic and SciELO databases, obeying the temporal cut that comprises the years 2020 to 2021. It was found that the use of active methodologies for teaching mathematics enhances the assimilation of content and allows a more meaningful learning on the part of students. This is because by presenting the contents in a contextualized way, it becomes possible to assign meaning to the math curricular themes that are being worked on.

Keywords: Education. Exact Sciences. Curriculum. Contents.

Resumen: Las metodologías activas se aplican en el proceso de enseñanza-aprendizaje con el fin de promover una asimilación activa de los contenidos, permitiendo al alumno liderar la adquisición de conocimientos. El uso de estas metodologías posibilita una mayor implicación del alumno con su aprendizaje, aumentando las posibilidades de comprender, de forma contextualizada, lo que se le presenta. En este sentido, se plantea que el objetivo general de este estudio es analizar la importancia de las metodologías activas para la enseñanza de las matemáticas. La metodología utilizada en la elaboración de esta investigación es la revisión de la literatura construida a partir del análisis de artículos científicos publicados y seleccionados a través de las bases de datos Google Academic y SciELO, obedeciendo al corte temporal que comprende los años 2020 a 2021. Las metodologías activas para la enseñanza de las matemáticas potencian la asimilación de contenidos y permite un aprendizaje más significativo por parte de los estudiantes. Esto se debe a que al presentar los contenidos de manera contextualizada, es posible asignar significado a los temas matemáticos curriculares que se están trabajando.

Palabras-clave: Educación. Ciencias Exactas. Plan de estudios. Contenido. 


\section{INTRODUÇÃO}

Os procedimentos associados ao ensino são importantes quando se trata da aprendizagem, dessa forma, as técnicas do ensino tradicional fazem parte de uma comunidade intelectual voltada a identificar possíveis deficiências que buscam implementar novas metodologias de ensino-aprendizagem. Assim, as metodologias ativas são mecanismos utilizados para identificar diferentes modelos e estratégias para a operacionalização do ensino, constituindo alternativas para o processo do aprendizado com inúmeros desafios e benefícios em diferentes níveis educacionais. A principal característica dessa metodologia é o foco social e político, ou seja, é compreendido que a educação se configura como um processo que não é neutro e as metodologias ativas seguem rumos com propostas educativas que se constituem como necessidades inerentes a atualização de processos educacionais da atualidade (Azevedo \& Maltempi, 2020).

Existe uma preocupação quando se trata das metodologias de ensino e das consequências do seu uso efetivo, desse modo, a forma de que os ensinamentos irão ser repassados podem ter caráter decisivo acerca da formação da mentalidade do aluno, bem como, do seu sistema de valores. É uma perspectiva inovadora para as instituições de ensino, já que exige mudanças didáticas no currículo escolar que estão sobrecarregadas nos conteúdos para a vida profissional e é importante que os problemas atuais exigem competência que vai além do conhecimento específico. É preciso que os educadores saibam ter habilidades voltadas para inovação, trabalho em grupo, educação para o desenvolvimento sustentável e globalizado, compreendendo que os problemas enfrentados pela sociedade não devem ser entendidos de forma individual, e sim, dentro de um contexto em conjunto (Sousa, Chaves \& Lima, 2021).

Ocorre a promoção de um currículo mais flexível e com organização pedagógica, conferindo ao professor a autonomia necessária, maior responsabilidade nas estratégias de ensino e na avaliação, além da produção de cenários da aprendizagem e materiais curriculares. Neste sentido, o currículo flexível pode articular a reforma curricular de acordo com as alterações do trabalho que foram provocadas por meio da reestruturação da produção, interferindo no conhecimento e na formação curricular. Dessa forma, o ensino ativo engloba demais termos como a aprendizagem colaborativa e a cooperativa, havendo a discussão entre a relação do significado de colaboração e cooperação (Fagundes, Brod \& Lopes, 2021).

As metodologias ativas são estratégias específicas que visam estimular o protagonismo do aluno, fazendo com que eles se tornem responsáveis pelo próprio processo de aprendizagem. A prática destas metodologias acontece a partir de uma assimilação ativa dos conteúdos socioculturais, significando que o educando assimila os conteúdos com os demais através de atividades de internalização do conteúdo. Quando se trata da disciplina de matemática é importante que os educadores saibam lecionar os assuntos da melhor forma possível, especialmente por envolver cálculos e raciocínio lógico, as metodologias ativas são fundamentais durante o processo para qualquer matéria (Fagundes, Brod \& Lopes, 2021). Nesse sentido, afirma-se que objetivo do 
presente estudo é o de analisar a importância das metodologias ativas para o ensino da matemática na Educação Básica, mais precisamente no Ensino Fundamental.

\section{MATERIAL E MÉTODOS}

\subsection{Caracterização da pesquisa}

A presente pesquisa é do tipo revisão bibliográfica. Este tipo de revisão é, de forma geral, a revisão das pesquisas e das discussões de outros autores sobre o tema que será abordado em seu trabalho. Ou seja: é a contribuição das teorias de outros autores para a sua pesquisa (Menezes, Duarte \& Carvalho, 2019). A pesquisa contou com a análise crítica de 10 artigos publicados em periódicos científicos entre os anos de 2020 a junho de 2021, considerando que se teve como proposta compreender o panorama da temática a partir de uma perspectiva mais atual. As bases de dados e periódicos eletrônicos utilizadas para a seleção dos mencionados artigos foram: Scientific Electronic Library Online e Google Acadêmico. Os critérios de exclusão foram artigos que não versam a respeito, especificamente, a respeito da aplicação das metodologias ativas ao ensino da matemática. Já os critérios de inclusão foram artigos em língua portuguesa e aqueles que envolvessem, especificamente, aplicação das metodologias ativas ao ensino da matemática.

Além disso, é importante destacar que os descritores utilizados na busca das referências foram: "metodologias ativas", "matemática" e "aprendizagem". Com isso, todos os estudos foram devidamente analisados, selecionados de acordo com o tema apresentado, título e conteúdo para a construção do estudo.

\section{RESULTADOS}

Em um ambiente puramente educacional ocorre a troca de experiência vivenciadas entre os alunos e professores, no qual, o estudante possui um grande espaço para colocar em prática o aprendizado críticoreflexivo diante de inúmeras situações. Dessa forma, o processo de ensino-aprendizagem está presente no cotidiano da sala de aula fazendo parte dos relacionamentos sociais, bem como, no ambiente escolar que é preciso que ocorra o desenvolvimento sadio entre a relação professor e aluno para fins didáticos educativos. Os ensinamentos podem ser marcados por procedimentos onde a experiência e a cultura são transmitidas pelo educador ao aluno, ou seja, se configura como um conjunto de técnicas relacionadas com a transmissão de saberes (Azevedo \& Maltempi, 2020).

O papel do educador é de facilitar o caminho da aprendizagem e caminhar em direção ao conhecimento, com inúmeros recursos que devem favorecer o ensino crítico-reflexivo do aluno de forma motivacional. A ação do docente está pautada na formação efetiva do aluno para contribuir na construção de uma sociedade que pensa por si só, sendo necessário ter em mente que o professor deve possuir uma formação do tipo reflexiva seguindo as bases do ensino reflexivo, além de possuir um pensamento de caráter instrumental originando o 
conflito de situações potencialmente problemáticas, e é importante para que o educador saiba se comportar diante desse tipo de confrontos (Sousa, Chaves \& Lima, 2021).

As Metodologias Ativas se constituem como a evolução do aprendizado dentro de sala de aula, além de utilizar experiências reais com intuito de solucionar desafios que advém de situações sociais, com diversos contextos inclusos. As instituições de ensino possuem diversos problemas na comunidade onde estão inseridas, e o estudante não está preparado para lidar com alguns conflitos, assim, essa forma de ensino é fundamental para a formação dos jovens que futuramente podem superar e aprender a solucionar os problemas de uma forma geral. Esse tipo de metodologia é um recurso didático do ensino-aprendizagem que objetiva alcançar os estudantes, colocando-os diante de conflitos, e eles devem realizar reflexões e ressignificar descobertas (Lubachewski \& Cerutti, 2020).

Os educadores fazem uso desse mecanismo com intuito de favorecer o processo de ensinoaprendizagem que é entendido como uma grande dimensão ético-social, que foram aplicadas nos anos 80 com objetivo de fornecer respostas diante da variedade de questionamentos que cercam a educação. É um instrumento utilizada na resolutividade de problemas, quando se trata da estratégia da melhoria do aprendizado com intuito de motivar os alunos refletindo e ressignificando suas descobertas. Determinadas metodologias ativas possuem propostas que visam alcançar a realidade dos alunos, bem como, o planejamento da aula que é fundamental para que o professor considere as habilidades e competências inerentes aos alunos. As metodologias ativas têm como principal objetivo propor um ensino mais ativo estimulando a motivação de conhecimentos fazendo com que os estudantes possam observar situações do cotidiano de maneira mais atenta e consciente (Oliveira et al., 2021).

Nesse sentido, a autonomia do aluno é importante quando se trata do processo das metodologias ativas, especialmente no processo pedagógico, onde o ensino ativo está associado ao desenvolvimento intelectual do estudante que busca uma consciência crítica sobre sua visão de mundo. Assim, o estudante irá construir linhas de pensamento ao invés de apenas seguir o que o professor fala em sala de aula, tomando uma postura mais ativa de acordo com o que é estimulado e argumentado, o mesmo sente mais estímulos para constituir um determinado conhecimento ao invés de apenas recebê-lo (Bellotto \& Petry, 2020).

As instituições de ensino devem buscar superar determinadas adversidades, já que o ensino ativo implica em novos tipos de aprendizagem e do desenvolvimento de competências do aluno, no sentido de fazer com que o docente inicie uma dimensão mais ética e política. O aprendizado compreende o desenvolvimento no campo intelectual do aluno, e é importante levar em conta suas operações mentais, como, a capacidade de pensar, refletir, comparar, criticar, argumentar diante de situações (Fagundes, Brod \& Lopes, 2021).

O ensino não deve ser reduzido ao aprendizado de ouvir informações, e é essencial que ocorra o desenvolvimento de aspectos emocionais durante o decorrer do caminhar educacional relacionado ao aspecto contínuo do conhecimento de si mesmo, bem como, suas potencialidades. Para o professor é importante que se tenha abertura de espaços para obter o conhecimento de seus alunos, sensibilizando-os para que aos poucos 
desenvolvam a segurança emocional e superando traumas, desenvolvendo novas vivências profissionais. No contexto educacional, existem diversas mudanças que exigem novas habilidades sociais, ou seja, quando se trata da quantidade de informações disponíveis da era tecnológica que está ao alcance de sujeito em alta velocidade através da comunicação cada dia mais avançada (Lubachewski \& Cerutti, 2020).

Há um grande número de pessoas que são atingidas para que seus principais objetivos sejam contemplados diante da situação atual, necessitando do posicionamento do indivíduo, assim, é preciso repensar o modelo de aula clássica das instituições de ensino com a imagem autoritária do professor, onde o aluno é considerado um membro passivo nesse processo. As metodologias utilizadas pelos professores ainda não conseguem se articular ao modelo de ensino, pois é compreendida que a ênfase está voltada aos conteúdos lecionados de maneira passiva aos alunos, ao invés de acontecer a motivação do pensamento crítico (Rocha \& Farias, 2020).

No ensino tradicional, os educadores podem garantir que todos os estudantes possam aprender o mínimo esperado diante dos conceitos básicos aprofundados, depois que os mesmos conseguem desenvolver o domínio básico da leitura e escrita é possível inverter o processo. Dessa forma, as informações básicas a respeito de determinado tema são acessadas por cada aluno de maneira flexível e com apoio direto dos educadores, sendo um conceito de aula invertida no qual há materiais sobre qualquer assunto e o aluno pode recorrer por ele mesmo, em seu ritmo (Sousa, Chaves \& Lima, 2021).

Nessa perspectiva, o professor pode propor um estudo mais aprofundado do tema fazendo com que o aluno possa buscar informações por si só, e em seguida é efetuada a avaliação pedindo que a turma responda três a quatro questões a respeito do assunto pedido. E na sala de aula, o professor deve orientar aos alunos que não adquiriram o básico em relação ao assunto oferecendo problemas de caráter mais complexo para os estudantes que conseguiram dominar o conteúdo. Frisando que o ensino deve partir de situações-problema, e as metodologias ativas têm objetivo de elevar o potencial dos alunos durante o processo de autonomia (Lubachewski \& Cerutti, 2020).

Assim, os alunos podem empregar conceitos estudados anteriormente para a análise e conclusões, que podem ser utilizados como estudo teórico com tema e finalidade de estimular os alunos para os estudos. É recomendado que haja possibilidade para os estudantes de manter um contato maior com situações que possam acontecer futuramente, sempre buscando habituá-los diante dos diferentes ângulos. O educador deve ter conhecimento acerca dos seus próprios conhecimentos relacionados a disciplina, havendo a bagagem cultural dos educandos e da forma que essas experiências sejam repassadas para o âmbito educacional (Carvalho et al., 2021).

Por esses motivos, afirma-se que as metodologias ativas têm o objetivo de fornecer uma educação de qualidade, no qual, os estudantes devem participar ativamente para construir seu próprio processo de aprendizagem no futuro, e ao mesmo tempo constituírem uma visão mais crítica diante da sociedade. Para que o processo funcione é importante não depender apenas do aluno, mas também dos educadores e das instituições 
de ensino que precisam colaborar para promover a autonomia dos discentes. No âmbito escolar as mudanças são fundamentais, já que o docente será o alvo principal quando se trata da renovação de paradigmas relacionados a mudança de parâmetros, sejam cognitivos, pedagógicos, psicológicos ou políticos, visando uma educação de qualidade e bem desenvolvida pelo aluno (Lima, Sousa \& Sitko, 2021).

\section{DISCUSSÃO}

O aprendizado é fundamental diante da dedicação por parte dos professores que passam a ter uma postura em maior grau com a interação entre os alunos, atuando quando é solicitado e precisam se expressar efetivamente cabendo ao educador reconhecer a forma e momento propício de intervenção para estimular a reflexão do aluno ou provocar um olhar sob outra perspectiva. A intervenção determina o clima de acolhimento essencial em processo de caráter coletivo de construção de conhecimentos destes jovens (Rocha \& Farias, 2020).

As mudanças na prática pedagógica não devem ocorrem de forma impositiva para o educador e nem para os alunos, assim, a opção da metodologia ativa deve ser efetuada de maneira completamente planejada previamente para não tirar a motivação do professor de lecionar. As metodologias ativas são uma forma de ensino-aprendizagem inovadoras para as escolas, no entanto, algumas ainda insistem em lecionar através de métodos tracionais, e os alunos são agentes passivos do aprendizado e dos conteúdos propostos. A participação dos professores na aceitação do ensino ativo é fundamental para a disseminação do conhecimento de forma consciente (Fagundes, Brod \& Lopes, 2021).

As instituições de ensino mostram novos caminhos quando se trata do modelo disciplinar que está modificado por modelos centrados nos aprendizados, a partir de atividades, jogos e leituras. Assim, para ocorrer essas mudanças de metodologias no currículo escolas, especialmente durante a participação de professores na organização das atividades didáticas e o tempo de aulas, as metodologias ativas são fundamentais durante esse processo. As modificações são necessárias quando se trata do aprendizado e para que o modelo tradicional não seja colocado como prioridade, os ajustes são necessários e profundos com foco em manter os alunos ativos com envolvimento direto no ensino (Rocha \& Farias, 2020).

O educador deve fazer o papel do orientador principal ministrando uma quantidade mínima de aulas, além de disponibilizar conteúdos importantes no espaço virtual. Nas metodologias ativas é fundamental que o processo deixe o aluno caminhar sozinho durante a aprendizagem, com os vídeos, leituras e atividades disponibilizadas fazendo com que a aula se desenvolva a partir de conhecimentos. Com isso, os professores podem organizar um projeto dentro do contexto da disciplina integrando os principais assuntos fazendo uso de pesquisa, entrevistas, narrativas e jogos como uma parte do ensino-aprendizagem.

Os alunos possuem papel importante durante o delineamento do processo dos métodos ativos, já que são fornecidas situações de aprendizagem envolvendo a problematização da realidade onde o mesmo está inserido, e irá interagir com o conteúdo dialogando de forma concisa. É importante salientar que o trabalho com 
metodologias ativas de ensino pode favorecer a interação entre os estudantes, como durante as aulas expositivas, no qual, os alunos estão sentados nas carteiras individuais e são "proibidos" de conversar com os colegas. As mudanças no processo de ensino-aprendizagem são difíceis, já que há uma busca para a ruptura com os modelos de ensino tradicional que irá abandonar o modelo de transmissão de conhecimentos, no qual o docente explica o assunto e os alunos apenas escutam (Carvalho et al., 2021).

Assim, na metodologia ativa o docente está em uma posição de facilitador no processo de aprendizagem, ou seja, havendo necessidade direta de envolver o aluno no ensino, o tornando protagonista de seu aprendizado e desenvolvendo o senso crítico diante da disciplina. Os procedimentos de ensino são importantes para conteúdos voltados da aprendizagem, as técnicas utilizadas no ensino tradicional possuem algumas falhas e buscam propor novas estratégias metodológicas de ensino-aprendizagem. As metodologias ativas relacionadas ao ensino-aprendizagem possuem como função compartilhar a preocupação e identificação a respeito dos diferentes modelos e estratégias a respeito de sua operacionalização, constituindo variadas alternativas para o processo de ensino com inúmeros benefícios em variados níveis (Lima, Sousa \& Sitko, 2021).

O educador tem o objetivo principal de contextualizar o aluno dentro de sua prática, sendo compreendido como um ser humano envolvido diretamente na prática transformadora do ensino agindo como agente integrante participativo e criando condições de desenvolvimento de práticas desejáveis para o grupo. Nessa senda, isto é, nesse rumo, o educador é constituído como um facilitador de conhecimentos e atua na mediação de aprendizados, fazendo uso de inúmeros recursos favorecendo o ensino crítico-reflexivo do aluno de maneira motivacional, com ação baseada em uma formação efetiva contribuindo para a construção de uma sociedade que pensa por si só. É necessário ter em mente que o professor deve ter uma formação reflexiva e que siga as bases do ensino reflexivo, com um pensamento caráter reflexivo com função instrumental originando o conflito de situações potencialmente problemáticas (Lubachewski \& Cerutti, 2020).

A respeito do ensino da matemática o melhor caminho é aproximar a teoria da prática, ou seja, conhecendo possibilidades de trabalho em sala de aula, no qual os problemas possam surgir da maneira contextualizada torna-se fundamental para que o educador construa um material pedagógico de qualidade. A matemática se destaca como um recurso metodológico, bem como um instrumento para a construção das estratégias envolvendo resolutividade. Nesse caminho, se configura como um método de investigação que faz uso da associação de estruturas matemáticas e variáveis com parâmetros que necessitam conhecer soluções com mais precisão (Azevedo \& Maltempi, 2020).

A Matemática é uma ciência que trabalha com abstração, assim, quando se faz o uso da modelagem matemática ocorre a aplicação de mecanismos de investigação que servem como um tipo de possibilidade para o ensino, no entanto, é preciso que os professores tenham cuidado para que não seja uma atividade apenas voltada para conceitos, e sim, fazendo com que o aluno realmente aprenda a montar modelos e adquirindo conhecimentos diversos. As Diretrizes Curriculares do Ensino Médio para Matemática possuem como pressuposto a contextualização e uma relação dos conteúdos matemáticos com situações de práticas de 
aprendizagem, dessa forma, a relação deve ser realizada de acordo com conceitos matemáticos associados a interdisciplinaridade (Lubachewski \& Cerutti, 2020).

A contextualização de conteúdos voltados para a matemática contribui para o aproveitamento por parte de cada estudante, por meio de relações existentes entre os conteúdos e o contexto social do mesmo, a partir daí se tem as metodologias ativas que estão baseada no ideal de relação entre o sujeito e sua realidade. Existem diversas situações dentro do contexto de cada aluno onde se pode desenvolver aprendizagem na área, como: fazer uso de elementos e conhecimentos científicos para diagnosticar questões sociais e ambientais; reconhecer o sentido histórico da ciência e tecnologia, percebendo o papel deles na vida humana e em diferentes épocas; realizar associação de conhecimentos e métodos científicos com a tecnologia do sistema produtivo; os estudantes podem enxergar a ciência como construção humana, buscando compreender como elas se desenvolveram através da acumulação ou ruptura de paradigmas; compreender a relação entre a evolução das ciências naturais e a tecnologias associando a diversas tecnologias no contexto atual; e entender o impacto das tecnologias na vida diárias, bem como, nos processo inerentes a produção e no desenvolvimento do conhecimento da vida social (Lima, Sousa \& Sitko, 2021).

As estratégias de ensino são uma resolução de problemas mais efetivas, ou seja, atuam como norteadoras da matemática no contexto escolar. Assim, a resolução de problemas auxilia no desenvolvimento de capacidades fundamentais para os alunos, como: a observação, estabelecimento de relações importantes entre eles, comunicação, argumentação, e estimulação para o raciocínio lógico. Nessa perspectiva, o educador deve propor atividades voltadas para a aplicação de conceitos matemáticos que não são suficientes para o sucesso do processo de ensino-aprendizagem. A matemática torna o aluno mais competente quando se trata da resolutividade de problemas engajando-os de maneira ativa para enfrentar desafios, com o uso de ferramentas tecnológicas para contribuir com o conhecimento em sala de aula (Fagundes, Brod \& Lopes, 2021).

É importante salientar que o uso de mecanismo tecnológicos contribui consideravelmente para o ganho de conhecimento, sendo inúmeros recursos tecnológicos disponíveis e ao alcance dos alunos, como, uma calculadora, celular, projetor de mídia, aplicativos e softwares. Todos esses recursos estão disponíveis e são parceiros dos professores, porém, nem todos os educadores aceitam utilizar tecnologia em sua aula. Para se trabalhar com matemática, os professores devem saber da relevância de promover no aluno a capacidade de aprender, especialmente quando se trata da resolução de problemas com a metodologia ativa, visando o desenvolvimento da capacidade de administrar informações que estão ao seu alcance ampliando-as de maneira que a assimilação de conceitos e procedimentos relacionados a matemática sejam eficazes (Carvalho et al., 2021).

Assim, é importante que haja compreensão do problema, elaboração do plano de aula, execução deste plano e realizar a verificação, corrigindo possíveis erros. Trabalhar com a resolução de problemas exige do educador um maior preparo e dedicação, como também, planejamentos elaborados de forma criteriosa para atender alunos que apresentam grandes dificuldades a respeito da aprendizagem de conteúdos matemática que 
são oferecidos de maneira abstrata e distante da realidade que os cercam. E muitas vezes acaba prejudicando a sua compreensão e interpretação dos problemas, levando-os ao fracasso (Bellotto \& Petry, 2020).

Quando a matemática é bem ensinada, a resolução de problemas pode ser vista como independente do desenvolvimento de ideias e processos matemáticos fundamentais, o trabalho acerca disso deve enfatizar a construção coletiva para os alunos que possui relação direta com a construção do saber. Dessa forma, ocorre a construção do suporte fundamental durante o processo de ensino-aprendizagem, possibilitando a comunicação social, a interação e a troca de informações em sala de aula, além de dar oportunidade para que os alunos construam significados. O caminho para que ocorra a satisfação entre os estudantes e educadores, e o sucesso da aprendizagem proporcionado através da autonomia ao cidadão faz com que o professor e aluno se sintam realização diante de suas expectativas, formando a corrente do sucesso da educação na matemática (Azevedo \& Maltempi, 2020).

O ensino da disciplina matemática vem enfrentando determinadas dificuldades, seja na parte dos estudantes quanto dos professores, e essas dificuldades se configuram como uma inserção de maneira inadequada de novas tecnologias na prática pedagógica dos professores, ou também a necessidade de se trabalhar a resolução de problemas de maneira efetiva. Sendo situações que precisam da utilização de recursos tecnológicos e metodológicos eficazes no contexto educacional, exigindo que o profissional tenha conhecimento e domine toda a sua prática docente, mas na grande maioria dos casos nossos professores nem tiveram contato com a metodologia ativa durante a sua formação, implicando em grande dificuldade para adequação de tais ferramentas em suas aulas (Carvalho et al., 2021).

O professor deve aprender a se comunicar de forma harmoniosa com os alunos, sendo uma fase caracterizada como contextualização de habilidades sociocomunicativas e requer paciência, além do uso tecnológico que é fundamental no ensino da matemática. É importante frisar que os alunos já nasceram numa era digital, ou seja, manuseando instrumentos de caráter tecnológico com mais facilidade e que muitos professores possuem dificuldade. Essa realidade a instituição de ensino deve evoluir em conjunto com a atualidade tornando-se uma mediadora entre o mundo real, e o mundo voltado para a tecnologia. A velocidade ocorre de forma que as mudanças acontecem, o que torna surpreendente como as metodologias ativas estão se adaptando efetivamente aos modelos de ensino tradicionais (Rodrigues et al., 2021).

As metodologias ativas se configuram como um tipo de estratégia didática voltada para o ensino, no qual, o personagem principal é o estudante. Composta por processos interativos do conhecimento, estudos, pesquisas e decisões individuais com finalidade de encontrar soluções para os problemas ou executar determinado projeto. Quando se trata do ensino da matemática, é essencial que os educadores tenham técnicas de ensino como um método ativo com características para identificar uma proposta efetiva, devendo ser construtiva, colaborativa, interdisciplinar, contextualizada, reflexiva crítica, investigativa e motivadora (Sousa, Chaves \& Lima, 2021). 
As metodologias tradicionais são antigas e estão desde sempre na educação, consistindo na ação de centralizar o professor como sendo o transmissor de todo o conteúdo, ou seja, ele é o 'único' detentor do conhecimento que é capaz de conduzir o aprendizado. Assim, as metodologias ativas estão fundamentadas na ideia de que o aluno é o sujeito ativo e a construção do conhecimento em situações que superem a tradicional aula de cunho expositivo. No Brasil, sua história remonta ao movimento da "escola nova", protagonizado por Anísio Teixeira e Lourenço Filho (Fagundes, Brod \& Lopes, 2021).

A utilização da metodologia ativa para a formação dos professores contribui para ação pedagógica do mesmo, ou seja, deixando de ser visto apenas como transmissor do aprendizado e passando a assumir o papel de facilitador e mediador do conhecimento. Por outro lado, o aluno passou a ser o receptor e autor de seu aprendizado, desenvolvendo autonomia e pensamento independente de caráter reflexivo. A aprendizagem ativa possui uma relação marcante com o aluno e o professor, estabelecendo um estímulo frequente de inúmeras construções mentais (Rodrigues et al., 2021).

As metodologias ativas possuem técnicas como, a Sequência Fedathi (SF), a Aprendizagem Baseada em Problemas (ABP) e a Sala de Aula Invertida, que são metodologias aplicadas em contexto virtual. A Sequência Fedathi (SF) é uma metodologia de ensino, onde o foco é a mudança da postura do professor a partir de ações que coloquem os estudantes em situação de aprendizagem. Foi criada pelo professor Doutor Hermínio Borges Neto, sendo desenvolvida para o ensino da matemática, possibilitando a modificação da postura do docente e ao mesmo tempo motivando o aluno a sair da zona de conforto instigando-o a raciocinar, além de incentivá-lo a desenvolver o raciocínio lógico e a capacidade do trabalho em conjunto (Carvalho et al., 2021).

A Aprendizagem Baseada em Problemas (ABP), foi idealizada em primeira instância no Canadá e foi adotada no Brasil, nas instituições estaduais e incorporada nos cursos de administração, medicina, arquitetura. É um método direcionado ao trabalho em grupo com no máximo de dez integrantes, facilitando a aplicação de atividades propostas pelo educador para que o mesmo venha mediar a discussões em conjunto. Nessa senda, o grupo irá discutir um problema, onde o texto permite que os estudantes se articulem de saberes prévios ambiente colaborativo, para estabelecimento de hipóteses e objetivos de aprendizagem que irão nortear o estudo (Sousa, Chaves \& Lima, 2021).

Frisando que o problema não diz respeito as junções de informações originadas pelos alunos, e estão baseados em textos que trazem situações de contexto na realidade do próprio aluno. Ocorre uma espécie de problematização diante dos textos fornecidos aos estudantes, sendo um caminho crucial a ser traçado gerando inúmeras reflexões e confrontos de ideias que estimulam a demonstração de algumas habilidades que ficam silenciadas quando estão no modelo de ensino tradicional. Outra metodologia ativa é a Sala de Aula Invertida, objetivando a construção do aluno com pensamento mais reflexivo, é compreendido que esse tipo de método otimiza o tempo em sala de aula para a matemática, pois os alunos passam a ter mais tempo para exercer sua autonomia e desenvolvimento do raciocínio lógico (Rocha \& Farias, 2020). 
O foco está em tornar a sala de aula um ambiente mais atrativo para os alunos da geração digital de forma a auxiliá-los em aprender, para ocorrer a aplicação da metodologia ativa, o professor deve obedecer a três etapas que são: antes da aula, durante a aula e depois da aula. Na primeira etapa, o educador deve selecionar questões problemáticas e expor para a turma fazendo uso de recursos tecnológicos como podcasts, vídeos que são facilitadores da aprendizagem. Durante a segunda etapa, é fundamental apresentar o material didático de forma a relacionar as questões propondo atividades para trabalhar as dificuldades que podem surgir para os alunos (Fagundes, Brod \& Lopes, 2021).

É fundamental fazer uso de gráficos para que o aluno tenha uma visão analítica para extrair informações, resolvendo o que foi proposto e pedido no problema. Assim, durante a terceira etapa, o professor deve organizar novas atividades, com intuito que o aluno possa revisar e aprofundar mais ainda seus conhecimentos. E é nessa fase que o estudante começa a tratar o material para a próxima aula presencial, repetindo o ciclo metodológico para cada aula durante o período letivo. As metodologias ativas podem ser utilizadas no ensino atual apresentando inúmeros benefícios, como: a flexibilização do acesso do aluno aos conteúdos lecionados, maior possibilidade de esclarecer as dúvidas em dois momentos, favorecer que o professor gerencie a sala de aula e fornecer credibilidade (Azevedo \& Maltempi, 2020).

O aluno deixa de ser um agente passivo ou decorador, passando a ser um indivíduo construtor de reflexões em defesa do seu ponto de vista exercendo o estado de autonomia, além do senso crítico. Com essas técnicas de ensino ocorre o auxílio da matemática, seja para o professor como para o aluno durante a construção do conhecimento de forma significativa, já que os resultados de um processo sistematizado de desenvolvimento podem fornecer subsídios concretos para um trabalho docente qualificado em um contexto diferente da sua formação. As metodologias ativas são vistas como possibilidades de ativar o aprendizado dos alunos, colocandoos como o centro de todo o processo educativo e é o contrário da metodologia tradicional (Oliveira et al., 2021).

A aprendizagem também pode ser realizada através do Project basead learning (PBL), que tem como objetivo fazer com que os alunos aprendam por meio da resolução colaborativa de desafios. Desse modo, a exploração dentro de um contexto específico de aprendizado por fazer uso de recursos tecnológicos, assim, a metodologia incentiva efetivamente habilidades relacionadas a reflexão acerca de problemas matemáticos (Rodrigues et al., 2021).

No contexto das metodologias ativas o professor pode atuar como mediador do processo de ensinoaprendizagem, no qual, possui o papel de intermediar o trabalho e projetos oferecendo retorno sobre a reflexão de caminhos tomados para a construção do conhecimento, estimulando a crítica dos alunos. Nas instituições de ensino, alguns professores podem fazer uso de estratégias puramente tradicionais com aulas expositivas, com instrumentos principais como o quadro negro ou giz, no entanto, outros profissionais fazem uso de práticas pedagógicas inovadoras com estratégias de ensino a serem exploradas (Rocha \& Farias, 2020).

Neste sentido, as metodologias ativas possuem um caráter inovador com descobertas do senso crítico dos estudantes havendo a participação ativa deles em trabalhos desenvolvidos em grupos, objetivando 
aprofundas os conhecimentos. É compreendido que os procedimentos de ensino são fundamentais quando se trata dos conteúdos voltados para a aprendizagem, onde as técnicas são utilizadas no ensino tradicional possuem determinadas falhas buscando propor novas estratégias metodológicas de ensino-aprendizagem (Lubachewski \& Cerutti, 2020).

\section{CONSIDERAÇÕES FINAIS}

Atualmente, o ensino está progredindo significativamente, especialmente quando se trata dos métodos mais inovadores que são as metodologias ativas que tem o dever de estimular as competências emocionais dos estudantes, além de auxiliar no papel do educador no momento de facilitar conhecimentos. Assim, os estudantes podem se tornar protagonistas e participar ativamente das produções dentro e fora da sala de aula abrindo novos caminhos que estão mudando de acordo com o aprendizado ativo.

No ensino da matemática existe o problema e o raciocínio lógico, e os educadores possuem técnicas pautadas na aprendizagem ativa a partir de desafios, leituras e atividades, sempre levando em conta os valores sociais de cada aluno. As metodologias ativas têm o uso validado quando se trata do currículo escolar, se configura como uma estratégia que deve ser mesclada como técnicas tradicionais de acordo com o conteúdo lecionado. Assim é compreendido que a diversidade dessas estratégias educativas atinge um maior número de alunos de acordo com suas particularidades e vivências. Vale lembrar que a aprendizagem ativa também auxilia significativamente demais disciplinas, não apenas a matemática, sendo considerada um mecanismo inovador para os educadores.

\section{Conflitos de interesses}

O autor declara que não há conflitos de interesse. Está ciente da submissão do artigo.

\section{REFERÊNCIAS}

Azevedo, G. T. de \& Maltempi, M. V. (2020). Processo de Aprendizagem de Matemática à luz das Metodologias Ativas e do Pensamento Computacional. Ciência \& Educação (Bauru), 26, e20061. https://doi.org/10.1590/1516731320200061

Bellotto, V. B., \& Petry, V. J. (2020). Desenvolvimento da Autonomia dos Alunos por meio de Metodologias Ativas e Híbridas no Ensino de Matemática. Proceeding Series of the Brazilian Society of Computational and Applied Mathematics, 7 (1). https://doi.org/10.1590/1426-731320200024

Carvalho, E. de F. G. (2021). et al. As tecnologias educacionais digitais e as metodologias ativas para o ensino de matemática. Brazilian Journal of Development, 7 (1), 3153-3169. https:/ / doi.org/10.548/4795-841320200045

Fagundes, G. D., Brod, F. A. T. \& Lopes, João L. B. (2021). O Ensino Híbrido nas aulas de Matemática do Ensino Fundamental. REVISTA EIXO, 10 (1), 53-64. https://doi.org/15.745/9854-731320200064 
Lima, V. R., Sousa, E. F. P., \& Sitko, C. M. (2021). Metodologias Ativas de Ensino e Aprendizagem: Sala de aula invertida, Instrução por colegas e Júri simulado no ensino de matemática. Research, Society and Development, 10 (5), e2810514507-e2810514507. https://doi.org/45.875/8266-788420200057

Lubachewski, G. C., \& Cerutti, E. (2020). Metodologias ativas no ensino da matemática nos anos iniciais: aprendizagem por meio de jogos. RIDPHE_R Revista Iberoamericana do Patrimônio Histórico-Educativo, 6, e020018e020018. https://doi.org/10.1590/1516-731320200061

Menezes, A. H. N., Duarte, F. R., Carvalho, L. O. R., \& Souza, T. E. S. (2019). Metodologia científica: teoria e aplicação na educação a distância. Brazilian Journal of Development, 7 (7), 66414-66430. https://doi.org/10.1590/1516-731320200061

Oliveira, R. R. (2021). et al. O software GeoGebra como aporte para o Ensino de Matemática e aplicação em sequências numéricas. Revista do Instituto GeoGebra Internacional de São Paulo, 10 (1), 92-107. https://doi.org/14.745/1516-731320200061

Rocha, C. J. T. \& FARIAS, S. A. (2020). Metodologias ativas de aprendizagem possíveis ao ensino de ciências e matemática. REAMEC-Rede Amazônica de Educação em Ciências e Matemática, 8 (2), 69-87. https://doi.org/41.785/1148-731320200074

Rodrigues, L. F. (2021). et al. O uso de tecnologias digitais como base de formação de professores que ensinam matemática. Brąilian Journal of Development, 7 (7), 66414-66430. https:/ / doi.org/10.1590/1516-731320200061

Sousa, E. F. P., Chaves, E. S., \& Lima, V. R. (2021). Sala de Aula Invertida: Uma Inversão na Aula de Matemática. Research, Society and Development, 10 (7), e20610716311-e20610716311. https://doi.org/41.158/1478731320200061

\section{Contribuições dos autores}

O artigo foi feito por um único autor, a motivação partiu da vivência em lecionar e conviver com o ambiente escolar por alguns anos, entendendo que se pode destacar ideias relevantes sobre o protagonismo dos estudantes no seu processo de aprendizagem da matemática. 